\title{
ORGANIZAÇÃO E TRABALHO NO JAPÃO
}

Características culturais e organizacionais japonesas e o desenvolvimento de formas eficazes de realização do trabalho.

Organizational and cultural Japanese characteristics and the development of more effective job doing.

PALAVRAS-ChaVE:

Japão, organização industrial, administração japonesa, aspectos culturais.

\section{KEY WORDS:}

Japan, industrial organization, cultural aspects, Japanese management.
* Doutorando em Administração na EAESP/FGV.

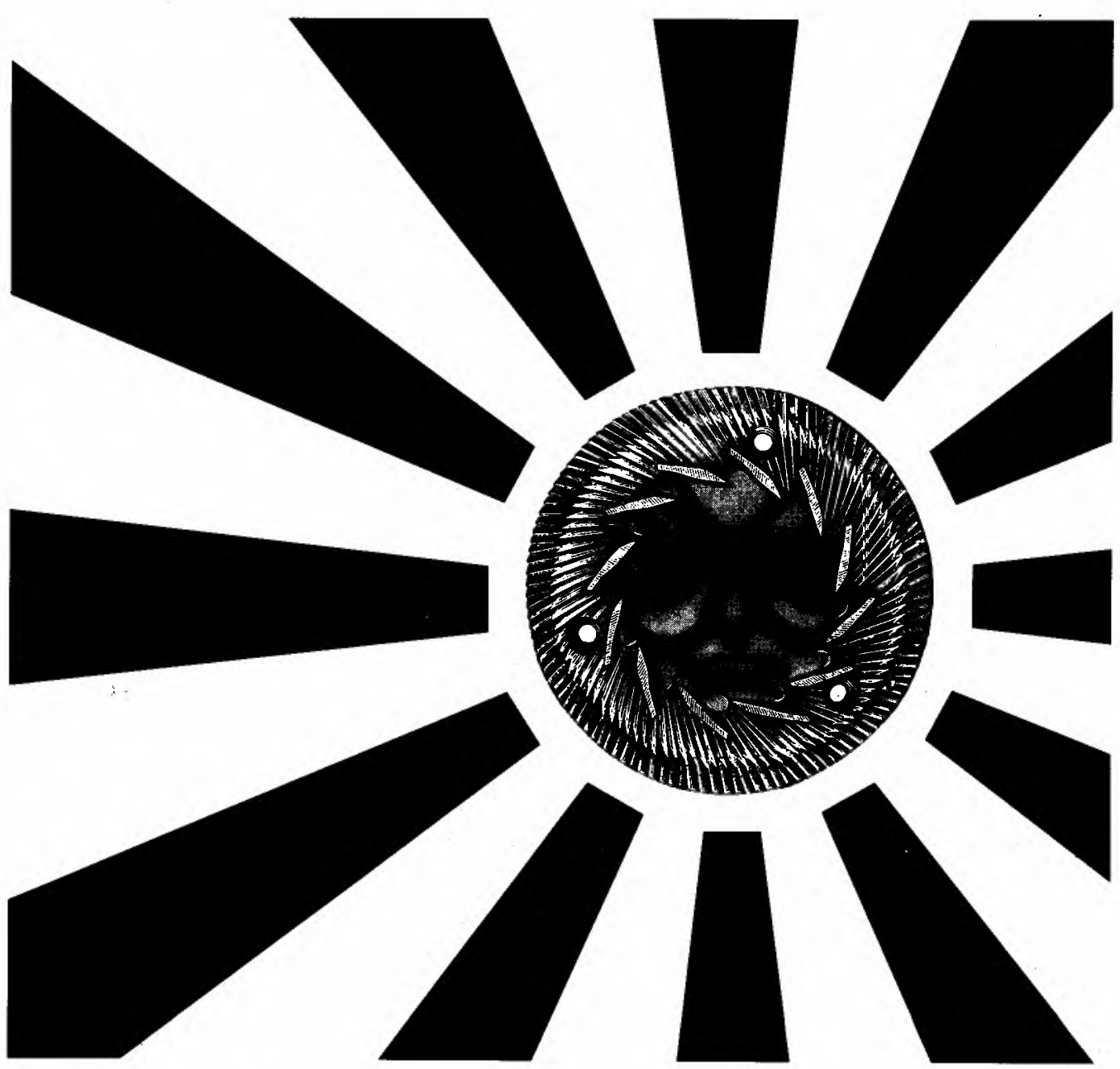

Jan./Fev. 1994 
Os princípios de organização racional do trabalho' popularizaram-se em todo o mundo durante o grande desenvolvimento industrial norte-americano. Após a Segunda Grande Guerra, devido à necessidade de reconstrução econômica do mun do, o interesse por um ou outro modelo de organização do trabalho tornou-se evidente para todos os países. Empregadores descobriram que deveriam olhar para além de seus países de origem e serem mais sensiveis ao contexto internacional.

Para a reconstrução econômica do mundo, o modelo americano de organização e gestão do trabalho foi escolhido. Governos e iniciativa privada enviaram numerosas missões aos Estados Unidos para estudar seus elevados níveis de produtividade. Trouxeram de volta aos seus países novas idéias e as particularidades do ambiente americano de negócios e relações industriais. Aspectos econômicos e culturais pareciam divergir dos praticados nos demais países.

Nos anos 60, foi a Alemanha que atraiu a atenção do mundo pelo rigor de seus métodos e o grande interesse em novas formas de administração e de democracia industrial. Na década seguinte, as atençōes voltaram-se para a Suécia, onde experiências com grupos semi-autônomos de produção aconteciam. Nesta mesma década, o Japão emergiu como potência econômica e passou a ser o focus de atenção do mundo.

Durante os anos setenta e oitenta, empregadores e estudiosos ficaram admirados com o desempenho da economia japonesa. Missões foram enviadas ao Japão para encontrar explicações para tão elevados níveis de desempenho e um novo modelo de administração foi descoberto. Evitar incertezas, pensamento de longo prazo, flexibilidade em todos os níveis da empresa e o famoso cooperativo espírito dos trabalhadores através das sugestões, círculos de controle de qualidade, filosofia just-in-time etc. passaram a ser enfatizados.

Uma olhada nas empresas japonesas mostrou aos administradores ocidentais potencial para aumentar a produtividade que até então não havia sido utilizado em suas empresas. Mostrou também que o campo da administração deveria abrir sua visão para além da manipula- ção de dados e resultados financeiros trimenstrais. A necessidade de estreitar a distância entre os trabalhadores e suas empresas foi assumida como prioritária mesmo reconhecendo a dificuldade de contabilizar as despesas necessárias para tal finalidade.

O Japão parece ter conseguido uma produção flexivel não somente através da cooperaçāo de seus trabalhadores em trocar de trabalho quando necessário, mas também mantendo os estoques nos menores níveis possíveis. As empresas japonesas mantêm também reduzido número de trabalhadores em atividades funcionais, não diretamente ligadas à produção. Grosseiramente não é demais afirmar

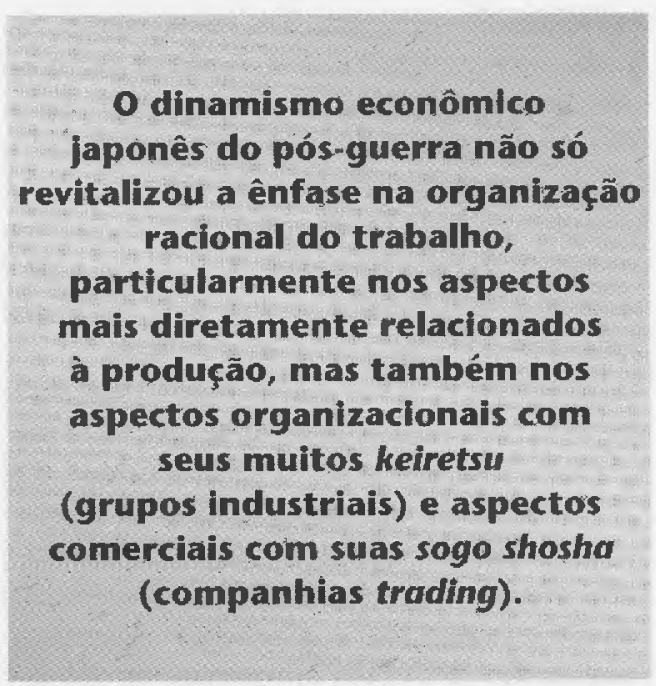

que o Japão é caracteristicamente um país produtor de manufaturados, enquanto que outros países como os Estados Unidos são mais orientados ao consumo de bens industrializados.

O dinamismo econômico japonês do pós-guerra não só revitalizou a ênfase na organização racional do trabalho; particularmente nos aspectos mais diretamente relacionados à produção, mas também nos aspectos organizacionais com seus muitos keiretsu (grupos industriais) e aspectos comerciais com suas sogo shosha (companhias trading). Revitalizou também a produção acadêmica nas áreas de economia e administração, que na sua maioria dispersou-se em discussões emocionais e ideológicas sobre a convergência ou divergência de modelos de desenvolvimento econômicos.
1. TAYLOR, F. W. Principios de administração científica. $7^{\text {a }}$ ed. São Paulo: Atlas, 1986. 
Neste artigo, procura-se introduzir ao administrador brasileiro alguns aspectos culturais e organizacionais japoneses relacionados ao trabalho produtivo. Procura-se sistematizar alguns. aspectos largamente divulgados na literatura acadêmica e de fácil compreensão e aplicação em qualquer ambiente de trabalho. Desnecessário dizer que todos os pontos abordados são discutíveis e merecem ser estudados com maior profundidade. Para tal finalidade um mínimo de bibliogafia é recomendada no final do artigo.

\section{ALGUNS ASPECTOS CULTURAIS}

Colegas japoneses do mundo acadêmico ou das grandes empresas estão sempre dizendo que uma das coisas mais difíceis para os japoneses é explicar as "coisas japonesas" para os estrangeiros. Este fato é também enfatizado em quase toda a literatura sobre administração japonesa. $\mathrm{Na}$ maioria dos casos, os mal-entendidos que sempre ocorrem não são somente devidos a vieses profissionais, mas também aos infinitos problemas lingüísticos.

Incompreensões idiomáticas parecem ser a característica mais comum de toda atividade acadêmica e profissional do Ocidente e do Oriente. Problemas relativos à comunicação são uma das principais barreiras entre países e empresas. Muitas vezes são a principal barreira dentro das próprias empresas. Se olharmos para dicionários japoneses ou livros preparados para ensinar a língua japonesa a iniciantes, ${ }^{2}$ nós podemos encontrar não somente as principais diferenças entre duas línguas, mas também muitas peculiaridades da língua japonesa. Uma delas é a utilização de três diferentes tipos de caracteres para expressar a si própria na forma escrita. Estes caracteres são o kanji, hiragana e katakana.

Kanji são os ideogramas chineses característicos da língua japonesa. Foram criados e desenvolvidos na China e importados pelo Japão ao redor do terceiro e quarto séculos do primeiro milênio da história cristã. Muitas palavras que indicam objetos e idéias podem ser escritas em kanji. Atualmente, existem 7.000 kanji e aproximadamente 2.000 deles necessitam ser aprendidos até o final da escola secundária. $\mathrm{O}$ ensino básico de primeiro (6 anos) e segundo (3 anos) graus é compulsório no Japão. Noventa e cinco por cento dos estudantes continuam seus estudos e $38 \%$ concluem os estudos universitários.

Hiragana é a forma arredondada do $\mathrm{ka}$ na. Hiragana é usado para se escrever partículas e terminações fonéticas não flexivas. Katakana é basicamente usado para representar o som das palavras estrangeiras. A forma dos caracteres katakana são diferentes dos kanji. Os caracteres kataka$n a$ apresentam distintivas formas angulares. Estes três tipos de caracteres requerem longas horas de treinamento e uma larga dose de paciência se alguém quiser não somente aprender a falar, mas também ler e escrever o idioma japonês.

Discutindo criatividade e formas de pensar, Makoto Kikuchi ${ }^{3}$ afirma que " $a$ maior deficiência dos ocidentais adultos que querem aprender a escrever ideogramas é que eles querem primeiro entender, quando tudo o que eles têm que fazer é imitar! Isto é igualmente verdadeiro para aprender a fazer arranjos de flores ou a contar o nagauta. $E$ geralmente aceito entre os japoneses que o significado original do termo manabu (aprender) era manebu (imitar). O mesmo método foi aplicado no aprendizado da tecnologia e indústria ocidental: reproduzir, imitar. No processo, entretanto, os japoneses aprendem 'padröes de reconhecimento', isto é, a capacidade de conceber a realidade não muito através da compreensão ('entender'), mas sim através da apreensão ('tomar por aquilo que é'), onde mente e corpo se ajustam à realidade."

O ajustamento da mente e do corpo dos japoneses à realidade começa nas pequenas organizações sociais como as famílias e continua através da formação escolar e do desenvolvimento de suas carreiras profissionais. Parte deste ajustamento é alcançado através de uma prática comum no Japão chamada ijime (na falta de melhor termo, intimidação em português). Intimidação por colegas de escola ou pelos mais velhos é parte do processo de socialização japonês. Existem alguns casos de intimidação maliciosa - abusos verbais, ostracismo, truques humilhantes etc. - que levam ao isolamento psicológico e afastamentos formais dos respectivos grupos que fazem parte. 


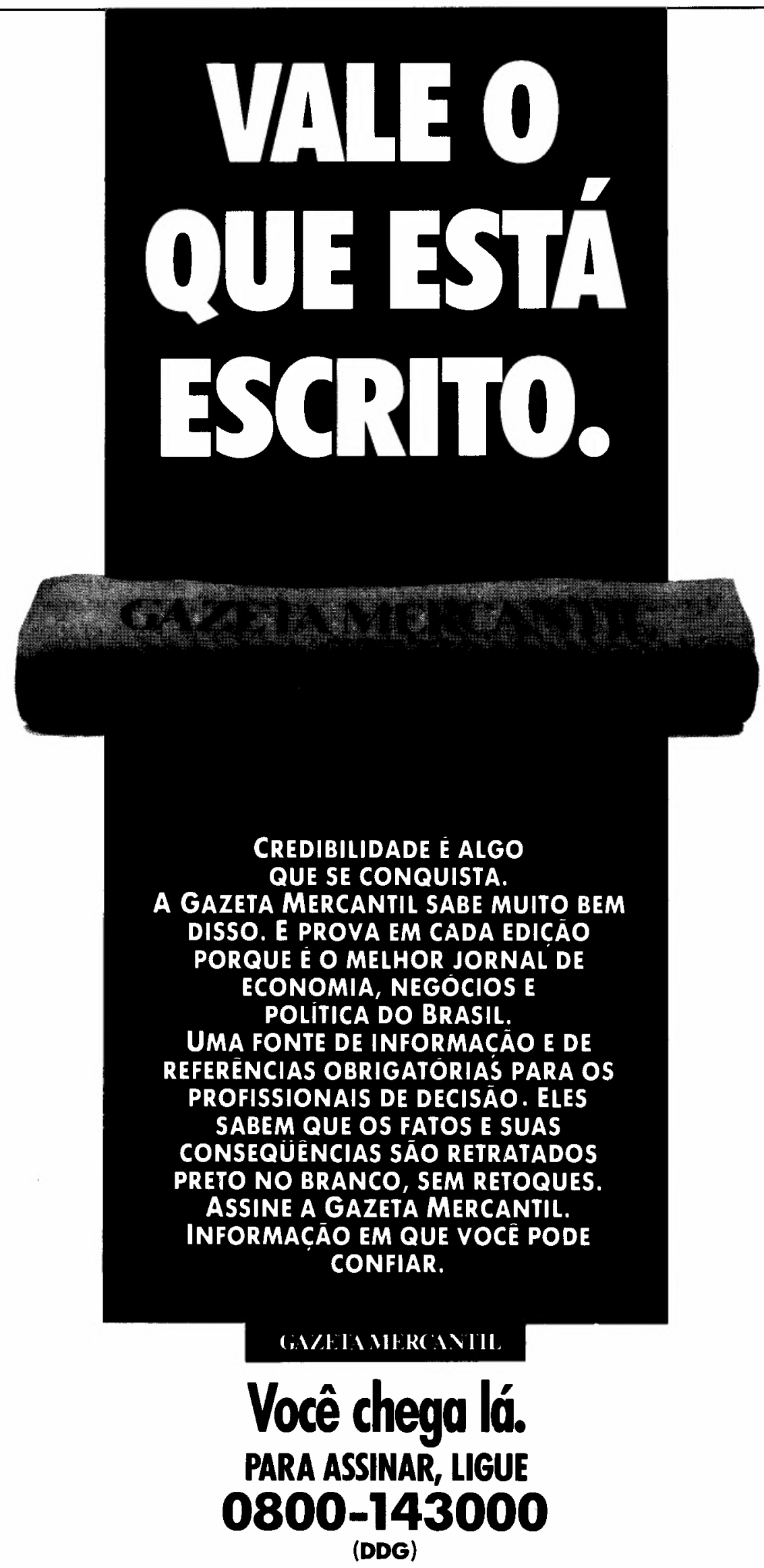


Uma vez que a criança torna-se um estigmatizado objeto de intimidação, seus amigos o abandonam. Esta é a causa de alguns suicídios de adolescentes no Japão, sendo o fracasso no vestibular japonês (juken jigoku - exames do inferno) uma outra causa freqüentemente relatada. O fenômeno da intimidação nos locais de trabalho pode ser visto quando alguns indivíduos são deliberadamente evitados e isolados por seus colegas de trabalho, ou mesmo em situações de con flito, onde superiores ou dois ou mais pressionam para convencer subordinados ou colegas a seguirem os interesses do grupo e não suas convicções pessoais. No local de trabalho, mais importante que os processos de intimidação é outro tipo de pressão social que possa ser sumarizada pela palavra ganbate.

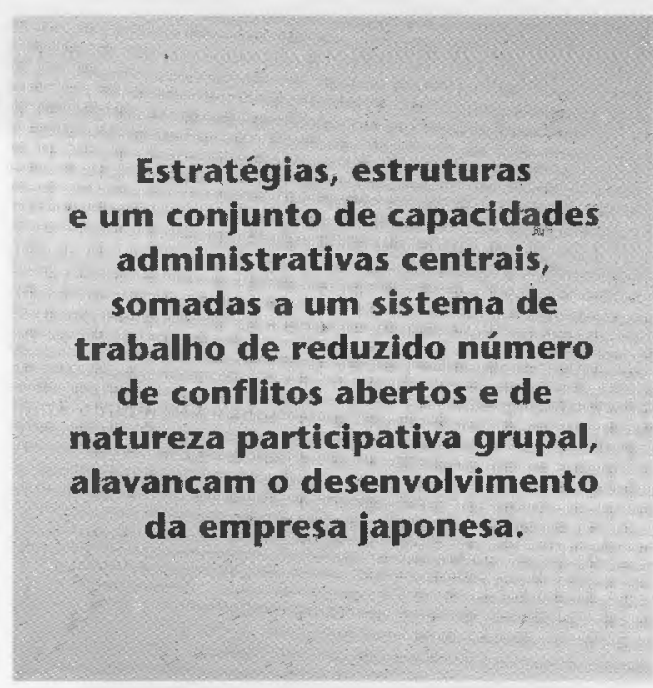

A palavra ganbate é a forma infinitiva do verbo ganbaru. O significado de ganbaru é permanecer firme, persistir num problema, insistir, superar-se, esforçarse. Sua forma infinitiva é usualmente usada quando um trabalhador está reclamando sobre suas dificuldades em terminar o trabalho para ele designado. Mesmo que os empregados japoneses estejam estressados por trabalhar longas horas, eles devem ganbate (fazer o seu máximo/melhor) para completar a atividade programada.

Mais dificil que trabalhar longas horas 4. SASAKI, Nanato. Management and industrial structure in Japan. Tokyo: Pergamon Press, 1981. $149 \mathrm{p}$. seja reduzido para 1.800 horas/ano) ou aprender a língua japonesa é compreender o real significado das palavras expressadas. Os japoneses estão sempre se expressando através das práticas conhecidas por honne (opinião real) e tatemae (opinião genérica). Honne é o que uma pessoa realmente pensa, é uma opinião pessoal. Tatemae é a política oficial ou a opinião do grupo. Freqüentemente os japoneses apresentam publicamente as politícas oficiais, enquanto no interior de seus grupos, expressam suas diferentes opiniões.

No nível social, o sentido de pertencer a um grupo parece ser no Japão muito mais forte que o sentido da individualidade. Mesmo em reuniões de negócios, muitas opiniões não são clara, extensiva e racionalmente discutidas entre pessoas de diferentes grupos ou, o que também é comum, entre grupos de japoneses e um ou dois homens de negócios ocidentais. Nas relações com estes últimos, existe muito espaço para incompreensões e desentendimentos. Estes, geralmente, cul minam em comentários preconceituosos e excessivamente emocionais de parte de orientais e ocidentais.

Aspectos ideológicos e emocionais de orientais e ocidentais são sempre muito difíceis de serem concebidos como um "padrão de conduta". No processo de formação da sua tradicional sociedade nacionalmente integrada, os japoneses têm constantemente sofrido conflitos entre a razão e a emoção, entre universalidade e etnicidade ou entre a dicotomia oriente e ocidente de forma mais intensa que qualquer outro povo asiático. Considerando a herança cultural como uma táboa de tradicionais e importados sistemas que o princípio "espírito japonês e tecnologia ocidental", seguido por todos os industrialistas desde a Restauração Meiji (1867) sintetiza, Nanato Sasaki ${ }^{4}$ classifica três situações onde o conjunto de normas japonesas $(\mathrm{Nj})$ e o conjunto de normas ocidentais (No) funcionam diferentemente. São eles:

"Situaçăo 01; $N j=$ No: esta situação é comum quando o ambiente é estável e atividades rotineiras dominam os negócios diários. Neste caso, é muito natural se os estrangeiros pensarem que o estilo de administração no Japão é ocidentalizado. 
Situação 02; $\mathrm{Nj} \neq$ No: quando as incertezas começam a crescer, estes dois conjuntos começam a se separar ou rompem abruptamente. Aqui, gerentes agem como japoneses em um momento, e como ocidentais no momento seguinte.

Situação 03; Nj > No: uma crise ou uma dificuldade maior pode mudar em um instante um japonês ocidentalizado em um puro japonês que retorna e se apega ao conjunto de $\mathrm{Nj."}$

Um desafio para qualquer homem de negócios estudando o Japão ou se relacionando com administradores japoneses é descobrir "padrões de conduta" que lhe permitam reconhecer as três situações descritas. Esta é uma tarefa difícil para os estrangeiros, assim como para os próprios japoneses, uma vez que estas três situações podem ser aplicadas no interior do Japão, onde temos diferentes famílias, clãs e outros grupos que desenvolvem estratégias competitivas e estruturas cooperativas na opinião do professor de história de negócios W. Mark Fruin ${ }^{5}$ ou kyoryo$k u$ shi nagara kyoso (cooperando enquanto competindo) na opinião do jornalista de negócios William J. Holstein. ${ }^{6}$

\section{ALGUNS ASPECTOS ORGANIZACIONAIS}

O censo industrial japonês, realizado pelo Ministério de Comércio Internacional e Indústria (MITI) em 1989, mostra que as empresas japonesas com mais de 300 empregados representam somente $0.7 \%$ dos estabelecimentos industriais e são responsáveis por $25.9 \%$ das pessoas empregadas e $47.6 \%$ de toda a produção industrial. O censo mostra, também, que somente 662 empresas $(0.1 \%$ dos estabelecimentos industriais) empregam 1.439 .000 pessoas $(12.4 \%)$, que são responsáveis por $25.9 \%$ da produção industrial.

Essas empresas fazem parte de grupos industriais que formam o sistema econômico japonês denominado de "capitalismo de alianças" por Michael Gerlach ${ }^{7} \mathrm{em}$ seu estudo sobre a organização social dos negócios japoneses. Estes grupos industriais normalmente conhecidos por keiret$s u$ são basicamente de dois tipos: grupos conectados horizontalmente e grupos integrados verticalmente.
Grupos conectados horizontalmente atuam em praticamente todos os setores da atividade econômica englobando bancos, seguradoras, companhias trading e variadas indústrias. Os seis grupos mais conhecidos são: Mitsubishi, Mitsui, Sumitomo, Fuji (Fuyo), DKB e Sanwa. Os três primeiros são herdeiros dos grandes grupos familiares existentes antes da Segunda Grande Guerra denominados de zaibatsu, e os três últimos estão organizados ao redor de grandes bancos e empresas trading. Outros dois grupos de porte médio, o Tokai e o Banco Industrial do Japão, também figuram entre os mais conhecidos.

Grupos integrados verticalmente são grupos que se estruturam em torno de uma grande empresa como a Toyota, a Matsushita, a Sony etc. Em torno destas empresas, agrupam-se várias subsidiárias ou afiliadas que funcionam como fornecedoras e distribuidoras de bens e serviços do grupo. Alguns grupos verticais fazem parte dos grupos horizontais, como é o caso do Grupo NEC que pertence ao Grupo Sumitomo ou o Grupo de Indústrias Pesadas Mitsubishi que pertence ao Grupo Mitsubishi.

As principais características desses grupos industriais são:

a. reciprocidade da posse de ações;

b. formação de conselhos de presidentes;

c. envio de pessoal técnico e de direção às empresas subsidiárias ou afiliadas;

d.financiamento intragrupo via banco principal;

e. existência de uma grande empresa trading (sogo shosha);

f. transações comerciais intragrupo;

g. investimentos conjuntos em novas indústrias, pesquisa e desenvolvimento.

Esses grupos e as empresas que os compõem têm apresentado um dinamismo econômico muito superior às empresas americanas e européias. Muitas hipóteses e teorias macroeconômicas foram desenvolvidas para explicar a melhor performance da economia japonesa quando contrastada com a economia dos países ocidentais. Porém, se o desempenho econômico japonês é devido aos elevados níveis de poupança e investimentos no setor privado, ou se é devido a políticas
5. FRUIN, W. Mark. The Japanese enterprise system: competitive strategies and $\mathrm{COO}$ perative structures. New York: Oxford University Press, 1992.

6. HOLSTEIN, William J. The Japanese power game: What it means for America. New York: Plume, 1991.

7. GERLACH, Michael. Alliances capitalism: the social organization of Japanese business. Berkeley: University of California Press, 1992. 
8. MASIERO, Gilmar. The main aspects of the Japanese management and their implementation in selected countries. Tokyo: Institute of Developing Economies, Oct. 1993. econômicas orientadoras do setor privado, ainda é um problema muito discutido e não resolvido.

Hipóteses e teorias sobre a empresa japonesa e seu peculiar modelo de administração também procuram explicar o crescimento da empresa japonesa. Alguns enfatizam a promoção por antigüidade, emprego vitalício e o sindicato por empresas como os elementos centrais da administração japonesa. Já outros procuram enfatizar os aspectos relacionados à filosofia just-in-time, programas de sugestões, controle de qualidade total etc. como sendo os mais significativos do modelo e os que mais contribuem para a transformação e crescimento da empresa.

A contribuição desta ou daquela rotina administrativa varia de empresa para empresa e tem comportamento variado ao longo do tempo. No caso japonês, planejamento estratégico, produção eficiente, marketing e distribuição, estrutura flexível, controles financeiros, controles de pessoal e relações industriais são em ordem decrescente de importância as áreas da administração responsáveis pela evolução da empresa japonesa.

Estratégias competitivas orientadas para a produção, controle total da qualidade, estrutura orgânica com baixo nível de formalização, resolução de conflitos através de consulta extensiva, educação e treinamento no próprio trabalho, alta comercialização através de OEM (Original Equipment Manufacturing) e fraco poder do departamento de controladoria financeira são as variáveis apontadas pelas grandes empresas japonesas como as que mais fortemente contribuem para seu. crescimento. ${ }^{\mathrm{g}}$

Estratégias, estruturas e um conjunto de capacidades administrativas centrais somadas a um sistema de trabalho de reduzido número de conflitos abertos e de natureza participativa grupal, alavancam o desenvolvimento da empresa japonesa. A produtividade da empresa, ao invés da eficiência individual, é mais enfatizada. Flexíveis grupos de trabalho repartem conhecimentos, informaçōes, habilidades e experiências na realização e controle do fluxo de trabalho.

Não existindo diferenças acentuadas entre gerentes e trabalhadores, os mesmos repartem não somente o conheci- mento e as informações relativas ao fluxo de trabalho, mas também a responsabilidade pelo alcance do melhor resultado possível, em termos de qualidade e quantidade. Descrições minuciosas do trabalho não existem no Japão. Os trabalhadores desenvolvem suas tarefas individuais e comuns ao fluxo de trabalho em conjunto. Reconhece-se que o planejamento

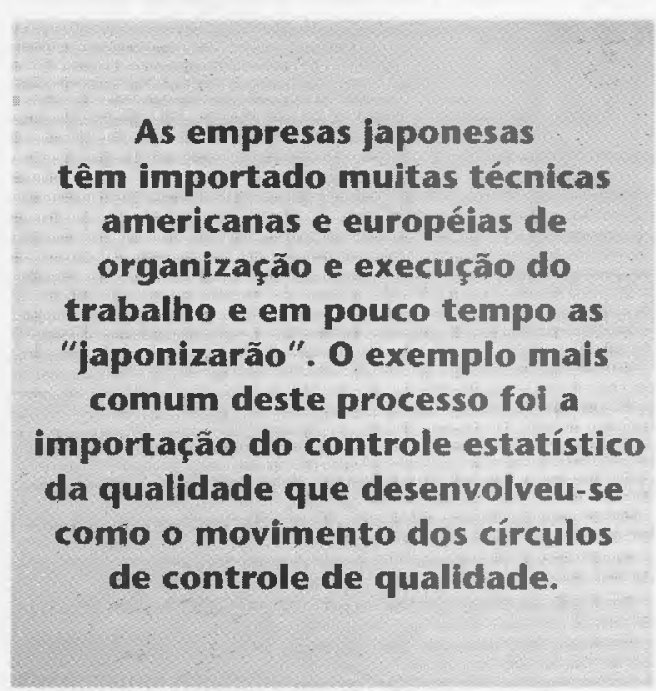

total ao nível da execução do trabalho é impossível e que as obrigaçōes podem variar de acordo com as circunstâncias ou fatores não controláveis pelo próprio trabalhador. A figura procura traduzir grosseiramente o sistema de trabalho no Ocidente e no Japão.

Nas empresas manufatureiras japonesas, a ênfase é dada aos chamados cinco esses é muito grande. Seiri, seiton, siso, seiketsu e shitsuke são palavras que traduzem respectivamente as idéias de evitar itens desnecessários, ordenar bem as coisas, limpar, manter limpo e preparado o local de trabalho e possuir a disciplina básica para realizar determinada atividade.

As empresas japonesas têm importado muitas técnicas americanas e européias de organização e execução do trabalho e em pouco tempo as "japonizarão". O exemplo mais comum deste processo foi a importação do controle estatístico da qualidade que desenvolveu-se como o movimento dos círculos de controle de qualidade, o controle de qualidade por toda a empresa, e agora é conhecido por qualidade assegurada e controle total da qualidade. 
Atualmente, todos estão envolvidos nos programas de controle total da qualidade. Gerentes, engenheiros, trabalhadores de escritório e de fábricas, vendedores, representantes e até fornecedores e clientes estão envolvidos nos programas de qualidade total. Num primeiro momento, o controle de qualidade começa pela eliminaçāo de produtos defeituosos, após inclui-se a prevenção desses mesmos defeitos e finalmente desenvolvemse melhores produtos.

\section{EFICÁCIA ADMINISTRATIVA}

O Produto Nacional Bruto de um país é o total de todos os produtos e serviços produzidos num determinado ano, descontados os custos das matérias-primas. É considerado a melhor medida da atividade econômica das naçōes. O produto nacional pode ser medido também através da despesa nacional. $\mathrm{O}$ produto japonês é $13 \%$ do produto do mundo sendo superado somente pelo produto americano que gira em torno de $23 \%$. Os Fstados Unidos exportam $11.7 \%$ e importam $16.2 \%$ e o Japão exporta o equivalente a $9.6 \%$ e importa $6.6 \%$ da produção mundial.

A poupança interna americana gira em torno de $16 \%$ enquanto que a japonesa $19 \%$ e as rendas percapita em torno de
US\$20.000 e US\$24.000 respectivamente. Embora estes números não retratem um menor poder aquisitivo dos japoneses frente aos americanos, eles retratam groseiramente quem produz e quem consome grande parte da produçāo mundial. Indicam também a importância que estes dois países representam para a economia mundial e de que forma o Japão está trabalhando para ser a primeira potência econômica do mundo.

Quanto a nós brasileiros e latino-americanos, resta-nos a possibilidade de desenvolver nosso potencial criativo na tentativa de construção de uma forma de organização racional do trabalho tropical, brasileira ou latino-americana, que se demons-

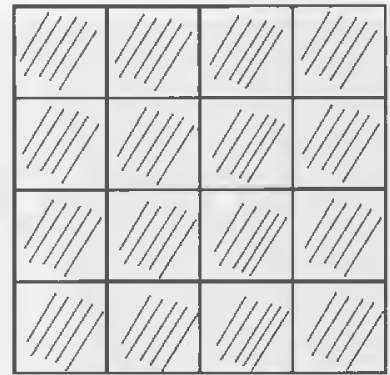

OCIDENTE

\section{IDEAL}

REALIZADO

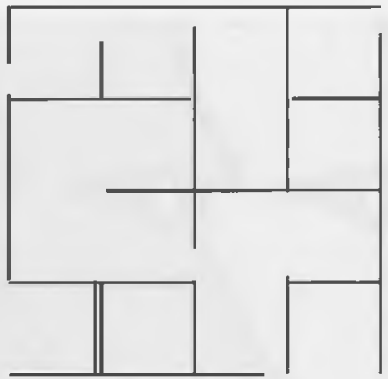

JAPÃO PRATICADO

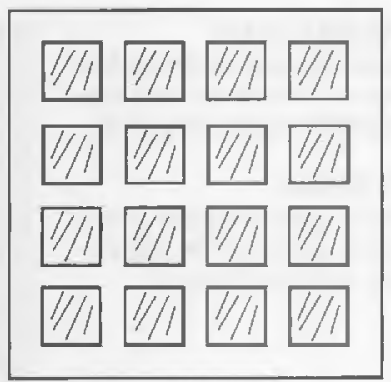

1//1] obrigaçōes individuais

obrigações do conjunto tre superior à japonesa ou à norte-americana. Caso contrário, engenharia reversa, benchmarking, reengenharia, administração por processos ou mesmo as velhas técnicas de estudo e organização do trabalho tayloristas estão aí para serem aplicadas.

\section{BIBLIOGRAFIA SUPLEMENTAR}

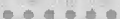

CLARK, Rodney. The Japanese company New Halen: Yale University Press, 1979.

DORE, Ronald. Brithish factory - Japanese factory. Berkeley: University of California Press, 1973.
DURLABHJI, Subhash, MARKS, Norton E. (ed.) Japanese business: cultural perspectives. New York: State University New York, 1993

HIRANO, Hiroyuki. Jif factory revoIution.Tokyo: Productivity Press, 1988
HIRCHMEIER, J., YUI, T. The development of Japanese business 1600-1980. London: Allen \& Urwin, 1981.

TSURU, Shigeto. Japan's Capitalism: creative defeat and beyond. New York: Cambridge University Press, 1993. ¿ 